\title{
Narrative review of intraoperative imaging guidance for decompression-only surgery
}

\author{
Sohrab Virk ${ }^{1}$, Sheeraz Qureshi ${ }^{2}$ \\ ${ }^{1}$ Department of Orthopedic Surgery, Northwell Health, Great Neck, NY, USA; ${ }^{2}$ Department of Orthopedic Surgery, Hospital for Special Surgery, \\ New York, NY, USA \\ Contributions: (I) Conception and design: All authors; (II) Administrative support: None; (III) Provision of study materials or patients: S Qureshi; (IV) \\ Collection and assembly of data: All authors; (V) Data analysis and interpretation: S Virk; (VI) Manuscript writing: All authors; (VII) Final approval \\ of manuscript: All authors. \\ Correspondence to: Sheeraz Qureshi. Department of Orthopedic Surgery, Hospital for Special Surgery, New York, NY, USA. Email: qureshis@hss.edu.
}

\begin{abstract}
Decompression of the spine is defined as removal of bony and soft tissue structures in order to provide space for the spinal cord and/or nerve roots. This definition, however, underscores the dangers and complexity of safely providing anatomical space for these neurologic structures. Complications such as neurologic injury, vascular injury, and durotomy can make these procedures hazardous for the patient and surgeon. Furthermore, inability to fully decompress the neural elements will result in continued symptoms for patients. Intraoperative image guidance can provide important anatomical landmarks to perform these decompressive surgeries safely and efficiently. In particular, performing decompression surgery utilizing minimally invasive techniques with image guidance can allow for the least amount of muscle/soft tissue trauma possible. Within our article we outline research on the forefront of use of intra-operative imaging guidance for spine surgery and implications for decompression surgery. We also outline a case from the senior author to illustrate an example of image-guided spine decompression for cervical radiculopathy. Future technology, such as augmented reality and robotics, is also discussed in the context of image guided decompression. The authors hope this article shows surgeons that use of image guidance in specific clinical situations can allow for better/safer spinal decompression procedures.
\end{abstract}

Keywords: Intraoperative imaging guidance; decompression-only surgery; localization

Submitted Aug 12, 2020. Accepted for publication Dec 24, 2020.

doi: 10.21037/atm-20-5854

View this article at: http://dx.doi.org/10.21037/atm-20-5854

\section{Introduction}

The three-dimensional anatomy of the spine is complex at baseline and can become significantly more difficult to visualize in the setting of spinal deformity (1). A precise understanding of this anatomy is key when performing any procedure on the spine given the proximity of critical nerves, spinal cord and vascular structures around the spine. There is general agreement that image guidance for accurate implant placement is critical for the spine in certain clinical applications (2). Initial research in the mid-1990s clearly demonstrated the potential benefits of image guided pedicle screw placement to improve accuracy and more recent literature has also supported this improved accuracy of pedicle screw placement using image guidance (3-6). Utilization of image-guidance for decompression-only surgery has been slower to develop for a variety of reasons, in particular proximity of crucial nerves, vascular structures and the need to preserve for bone for spinal stability.

Traditional techniques of decompression in the lumbar, thoracic and cervical spine rely on fluoroscopy for localization alone. After initial identification of the appropriate level for surgery, no further imaging is usually necessary. Anatomical landmarks visualized in open or minimally invasive surgery (MIS) guide the surgery regarding the bony/soft tissue structures required 
for removal. The authors of this review, however, have been able to incorporate image guidance within their surgical workflow to increase operating room efficiency and, in certain clinical situations, help perform a safer decompression procedure. Whether performing open dissection or operating through a tubular retractor, image guidance using new-age technology can improve surgical workflow.

Within our article we discuss the current state of literature regarding incorporation of image guidance during decompression-only spine surgery and then provide a clinical case where image guidance was especially helpful for one of our senior surgeons. We then discuss future innovation in the field and how traditional techniques might evolve in the coming years to incorporate advancements in image-guiding technology. We present the following article in accordance with the Narrative Review reporting checklist (available at http://dx.doi.org/10.21037/atm-20-5854).

\section{Current state of literature}

We performed a literature search using two online databases of articles. These included PubMed (Medline) and Scopus. We included the following search terms/phrases "imageguided decompression", "navigated spine decompression", "image-guided laminotomy", "navigated laminotomy" and "image guided spine decompression" between January, 1990 to July, 2020. Only English language articles were reviewed. Over 350 unique articles were identified using these search terms.

Numerous articles described using navigation in order to assist surgeons during anatomically complex decompressive procedures. Stavrinou et al. described use of navigation when performing extraforaminal decompression of the L5 nerve root (7). They reported their results on ten patients who received this treatment with significant improvements in pain scores comparing pre- and post-operative results. Yuan et al. described their technique for resection of ossified ligamentum flavum for thoracic myelopathy for 14 cases (8). A unique case report by Hartman et al. describes the use of navigation to remove extraforaminal extravasation of cement after a L5 vertebroplasty. Using a combination of spinal navigation and intra-operative computer tomography (CT) they were able to remove the cement extravasation (9). Computer navigation was used by surgeons in another 2002 study to remove tumor from the thoracic spine for 8 patients, but the authors highlight the fact that this technology should only be used/relied upon by experienced surgeons as accuracy isn't $100 \%$ (10). Choudhri et al. used navigation in order to properly decompress foramen magnum/odontoid for basilar invagination through a transnasal approach (11). Similarly, Hussain $e t$ al. utilized navigation in a two-stage procedure for decompression of the cervicomedullary junction for Chiari malformations via a transoral approach (12).

There have been several important case series that have demonstrated positive outcomes associated with the use of navigation in decompression-only spinal surgery. Cardali et al. used navigation in order to perform a MIS unilateral laminotomy with a crossover decompression as well. Their report of 25 patients was favorable especially when considering leg pain scores (13). Similarly, an "over the top" foraminal decompression was described by Kirnaz et al. and was used for a 51 year old with a recurrent foraminal disc herniation (14). Pirris et al. also used 3-dimensional image guidance for decompression of the subaxial cervical spine for 22 patients that required complex anterior cervical surgeries (15). Along with clinical results this article described the setup/technique for use of image guidance for decompression. In an earlier study by Sembrano et al., a review of 100 spine surgeries done with navigation revealed that approximately $38 \%$ of procedures navigation was used to assess the adequacy of decompression of the lumbar spine (16).

\section{Senior surgeon's case example}

In order to highlight the role of intraoperative image guidance for our clinical practice we present the case of a 25 -year-old female with severe neck pain and right arm weakness/numbness. In particular, she had weakness in her biceps on the right and numbness over her right thumb. This had persisted despite non-operative modalities of care for several weeks. Her pre-operative radiographs are shown in Figure 1 and her a relevant axial slice of her pre-operative imaging is shown in Figure 2. In Figure 2, a disc herniation is noted through the C5-C6 disc causing abutment of the exiting C6 nerve root. The patient was treated with a cervical foraminotomy for neurolysis of her C6 nerve root. Using image guidance, we were able to trace out the borders of the lamina/facet joint and visualize the cervical foramen. When performing our decompression we were able to use the navigation probe in order to gauge the depth of our bony resection in order to avoid injury to nerve roots. We used Stryker Navigation with Spine Mask $\left(\right.$ Stryker $^{\circledR}$ ) technology and an intra-operative CT scan. A Ziehm C-Arm (Ziehm Imaging $^{\circledR}$ ) was used for this scan (17). All members 


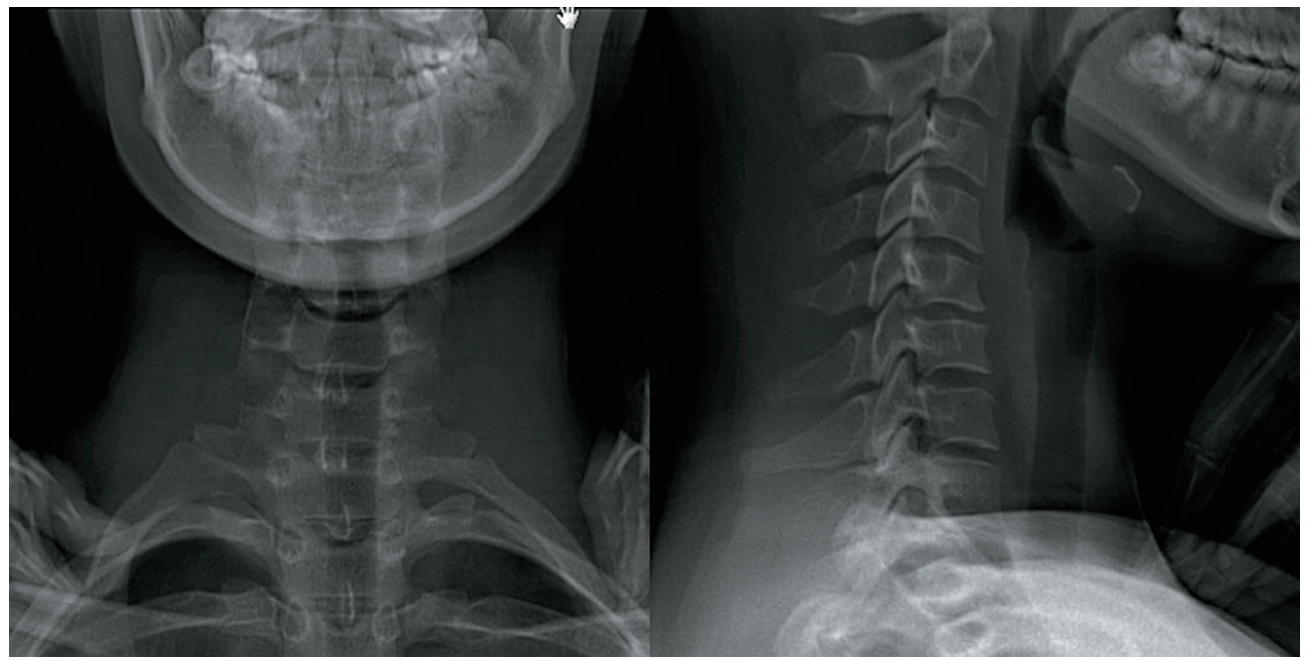

Figure $1 \mathrm{AP}$ and lateral radiographs of our patient with debilitating neck and arm symptoms. AP, anterior-posterior.

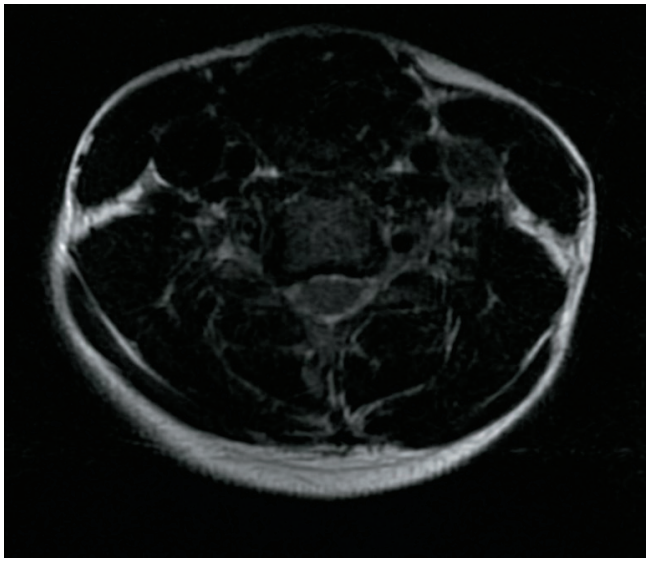

Figure 2 Disc herniation noted on axial slice of C5-C6 through the right foramen.

of the surgical team stepped away from the machine during the CT scan so as to avoid any radiation exposure.

\section{Future research and innovative technology}

Navigation in spine surgery is a developing field and there are several avenues of research that provide new ways to incorporate navigation for decompression-only surgery. Augmented reality allows for visualization of image guidance without having to look away from the surgical field. New devices incorporating augmented reality with a microscope can allow smoother utilization of image guidance in surgical workflow. Carl et al. published their experience with performing procedures on ten patients treated for spinal stenosis and disc herniations. They reported favorable results and provided illustrative examples of identifying anatomical landmarks such as the lamina, disc and facets with their technology (18). There is substantial evidence that augmented reality has promise in implant placement and the authors of this review believe further technologic development in this field will yield safer and more efficient decompression-only surgeries $(19,20)$. As the use of navigation increases with spinal decompression procedures the authors do want to emphasize the fact that over reliance on these technologies can in and of itself be a risk of use. Younger surgeons that have not learned the traditional methods of localization may have difficulty adjusting if a navigation system is down/broken.

Robotics for spine surgery has been heralded to provide better care for patients by utilizing image-guidance for placement of spinal implants (21). Further innovation is likely required, however, to help surgeons utilize robotic technology for separating neural elements from ligamentum flavum, intervertebral disc as well as epidural vessels. Accuracy of surgical robots have ranged from 1 to $4 \mathrm{~mm}(22,23)$. Given the risks of aberrant instrument placement during decompression, further research/work is required to improve this issue of accuracy particular with robotic navigation of instruments like a burr or Kerrison punch. Advancements in the communication between navigation software and robotic instrumentation holds the key to use of a robot for spinal decompression procedures (24).

A topic that warrants further research is streamlining 
communication between an instrument decompressing a portion of the spine and the real-time image a surgeon visualizes. By being able to track how much bone/ ligamentum flavum is being removed the surgeon could get a better sense of how close their instrument is located to such critical structures as nerves, spinal cord and/or vessels. Furthermore, there could be an alarm or signal to the surgeon when they might be removing too much bone and possibly creating an unstable segment (i.e., if they were taking too much of the bony pars). Further innovation is required in order to improve this real-time communication between navigation and such instruments like a burr, Kerrison, curette, etc.

\section{Conclusions}

This article attempts to capture the innovations in imageguidance that can be utilized for decompression-only surgery in spine. Our review of literature shows that there are several centers around the world that are pushing the limits of the technology to improve patient care. Further innovations can be expected from both augmented reality and the incorporation of image-guidance with robotic technology to help surgeons perform spinal decompressions better.

\section{Acknowledgments}

Funding: None.

\section{Footnote}

Provenance and Peer Review: This article was commissioned by the editorial office, Annals of Translational Medicine for the series "Current State of Intraoperative Imaging". The article has undergone external peer review.

Reporting Checklist: The authors have completed the Narrative Review reporting checklist. Available at http:// dx.doi.org/10.21037/atm-20-5854

Conflicts of Interest: Both authors have completed the ICMJE uniform disclosure form (available at http://dx.doi. org/10.21037/atm-20-5854). The series "Current State of Intraoperative Imaging" was commissioned by the editorial office without any funding or sponsorship. SQ served as the unpaid Guest Editor of the series and serves as an unpaid editorial board member of Annals of Translational Medicine from Sep 2019 to Aug 2021. Dr. SQ reports other from
Avaz Surgical, personal fees from Globus Medical, personal fees from Paradigm Spine, personal fees from Styker, personal fees from Vital 5, outside the submitted work; in addition, Dr. SQ has a patent Globus Medical with royalties paid, and a patent Styker with royalties paid. The other author has no other conflicts of interest to declare.

Ethical Statement: The authors are accountable for all aspects of the work in ensuring that questions related to the accuracy or integrity of any part of the work are appropriately investigated and resolved.

Open Access Statement: This is an Open Access article distributed in accordance with the Creative Commons Attribution-NonCommercial-NoDerivs 4.0 International License (CC BY-NC-ND 4.0), which permits the noncommercial replication and distribution of the article with the strict proviso that no changes or edits are made and the original work is properly cited (including links to both the formal publication through the relevant DOI and the license). See: https://creativecommons.org/licenses/by-nc-nd/4.0/.

\section{References}

1. Cromeens BP, Ray WC, Hoehne B, et al. Facilitating surgeon understanding of complex anatomy using a threedimensional printed model. J Surg Res 2017;216:18-25.

2. Härtl R, Lam KS, Wang J, et al. Worldwide survey on the use of navigation in spine surgery. World Neurosurg 2013;79:162-72.

3. Foley KT, Smith MM. Image-guided spine surgery. Neurosurg Clin N Am 1996;7:171-86.

4. Kalfas IH, Kormos DW, Murphy MA, et al. Application of frameless stereotaxy to pedicle screw fixation of the spine. J Neurosurg 1995;83:641-7.

5. Lee YC, Lee R. Image-guided pedicle screws using intraoperative cone-beam CT and navigation. A costeffectiveness study. J Clin Neurosci 2020;72:68-71.

6. Malham GM, Parker RM. Early experience of placing image-guided minimally invasive pedicle screws without K-wires or bone-anchored trackers. J Neurosurg Spine 2018;28:357-63.

7. Stavrinou P, Hartl R, Krischek B, et al. Navigated Transtubular Extraforaminal Decompression of the L5 Nerve Root at the Lumbosacral Junction: Clinical Data, Radiographic Features, and Outcome Analysis. Biomed Res Int 2016;2016:3487437.

8. Yuan Q, Zheng S, Tian W. Computer-assisted minimally 
invasive spine surgery for resection of ossification of the ligamentum flavum in the thoracic spine. Chin Med J (Engl) 2014;127:2043-7.

9. Hartmann S, Kavakebi P, Tschugg A, et al. Navigation for Tubular Decompression of the L5 Nerve Root Ganglion after Cement Leakage via a Wiltse Approach. Asian J Neurosurg 2019;14:565-7.

10. Arand M, Hartwig E, Kinzl L, et al. Spinal navigation in tumor surgery of the thoracic spine: first clinical results. Clin Orthop Relat Res 2002:211-8.

11. Choudhri O, Mindea SA, Feroze A, et al. Experience with intraoperative navigation and imaging during endoscopic transnasal spinal approaches to the foramen magnum and odontoid. Neurosurg Focus 2014;36:E4.

12. Hussain I, Schwartz TH, Greenfield JP. Endoscopic Endonasal Approach to the Upper Cervical Spine for Decompression of the Cervicomedullary Junction Following Occipitocervical Fusion. Clin Spine Surg 2018;31:285-92.

13. Cardali SM, Cacciola F, Raffa G, et al. Navigated minimally invasive unilateral laminotomy with crossover for intraoperative prediction of outcome in degenerative lumbar stenosis. J Craniovertebr Junction Spine 2018;9:107-15.

14. Kirnaz S, Wipplinger C, Schmidt FA, et al. Minimally Invasive Laminotomy for Contralateral "Over-theTop" Foraminal Decompression Using 3-Dimensional Total Navigation: 2-Dimensional Operative Video. Oper Neurosurg (Hagerstown) 2020;19:E296.

15. Pirris SM, Nottmeier EW. A case series on the technical use of three-dimensional image guidance in subaxial anterior cervical surgery. Int J Med Robot 2015;11:44-51.

Cite this article as: Virk S, Qureshi S. Narrative review of intraoperative imaging guidance for decompression-only surgery. Ann Transl Med 2021;9(1):88. doi: 10.21037/atm-205854
16. Sembrano JN, Santos ER, Polly DW Jr. New generation intraoperative three-dimensional imaging (O-arm) in 100 spine surgeries: does it change the surgical procedure? J Clin Neurosci 2014;21:225-31.

17. Vaishnav AS, Merrill RK, Sandhu H, et al. A Review of Techniques, Time Demand, Radiation Exposure, and Outcomes of Skin-anchored Intraoperative 3D Navigation in Minimally Invasive Lumbar Spinal Surgery. Spine (Phila Pa 1976) 2020;45:E465-76.

18. Carl B, Bopp M, Sass B, et al. Microscope-Based Augmented Reality in Degenerative Spine Surgery: Initial Experience. World Neurosurg 2019;128:e541-51.

19. Yoo JS, Patel DS, Hrynewycz NM, et al. The utility of virtual reality and augmented reality in spine surgery. Ann Transl Med 2019;7:S171.

20. Gottschalk MB, Yoon ST, Park DK, et al. Surgical training using three-dimensional simulation in placement of cervical lateral mass screws: a blinded randomized control trial. Spine J 2015;15:168-75.

21. Joseph JR, Smith BW, Liu X, et al. Current applications of robotics in spine surgery: a systematic review of the literature. Neurosurg Focus 2017;42:E2.

22. Overley SC, Cho SK, Mehta AI, et al. Navigation and Robotics in Spinal Surgery: Where Are We Now? Neurosurgery 2017;80:S86-99.

23. Chen L, Zhang F, Zhan W, et al. Research on the accuracy of three-dimensional localization and navigation in robotassisted spine surgery. Int J Med Robot 2020;16:e2071.

24. Vo CD, Jiang B, Azad TD, et al. Robotic Spine Surgery: Current State in Minimally Invasive Surgery. Global Spine J 2020;10:34S-40S. 